Journal for ImmunoTherapy of Cancer

\title{
Tumor-draining lymph node is important for a robust abscopal effect stimulated by radiotherapy
}

\author{
Zachary S Buchwald (1) ,1,2 Tahseen H Nasti, ${ }^{2}$ Judong Lee, ${ }^{2}$ \\ Christiane S Eberhardt, ${ }^{2}$ Andreas Wieland (D) , ${ }^{2}$ Se Jin Im, ${ }^{2}$ David Lawson, ${ }^{3}$ \\ Walter Curran, ${ }^{1}$ Rafi Ahmed, ${ }^{2}$ Mohammad K Khan ${ }^{1}$
}

To cite: Buchwald ZS, Nasti TH, Lee J, et al. Tumor-draining lymph node is important for a robust abscopal effect stimulated by radiotherapy. Journal for ImmunoTherapy of Cancer 2020;8:e000867. doi:10.1136/jitc-2020-000867

- Additional material is published online only. To view please visit the journal online (http://dx.doi.org/10.1136/jitc2020-000867).

THN and JL contributed equally. Accepted 18 August 2020

Check for updates

(C) Author(s) (or their employer(s)) 2020. Re-use permitted under CC BY-NC. No commercial re-use. See rights and permissions. Published by BMJ.

${ }^{1}$ Department of Radiation Oncology, Emory University, Atlanta, Georgia, USA

${ }^{2}$ Emory Vaccine Center, Department of Microbiology and Immunology, Emory University, Atlanta, Georgia, USA ${ }^{3}$ Department of Hematology and Oncology, Emory University, Atlanta, Georgia, USA

Correspondence to Dr Mohammad K Khan; drkhurram2000@gmail.com

\section{ABSTRACT}

Background Radiotherapy (RT) has been shown to stimulate an antitumor immune response in irradiated tumors as well as unirradiated distant sites (abscopal effect). Previous studies have demonstrated a role for the tumor-draining lymph node (LN) in mediating an anti-programmed death-1 (PD-1)/programmed death ligand-1 (PD-L1) stimulated antitumor immune response. Here, we investigated whether the LN is also important in mediating a RT alone stimulated abscopal response.

Methods We used a subcutaneous modified B16F10 flank tumor model injected bilaterally. Our B16F10 cell line has an inserted viral glycoprotein which facilitated identification of tumor-specific T-cells. RT was directed at one flank tumor alone or one flank tumor and the tumor-draining LN. We evaluated response by tumor growth measurements and flow cytometry of both tumor-infiltrating and LN T-cells.

Results We show that local tumor irradiation improves distant tumor control (abscopal effect). Depletion of $\mathrm{CD}^{+} \mathrm{T}$-cells significantly reduced this abscopal response. We have previously shown, in a chronic lymphocytic choriomeningitis virus (LCMV) infection, that the T-cell proliferative burst following blockade of PD-1/ L1 is provided by a 'stem-like' CD8 ${ }^{+} \mathrm{T}$-cell subset which then differentiate into terminally differentiated effectors. These terminally differentiated effectors have the potential to kill virally infected or tumor cells following PD-1/L1 blockade. In the chronic LCMV infection, stemlike CD8 ${ }^{+}$T-cells were found exclusively in secondary lymphoid organs. Similarly, here we found these cells at high frequencies in the tumor-draining LN, but at low frequencies within the tumor. The effect of RT on this T-cell subset in unknown. Interestingly, tumor irradiation stimulated total $\mathrm{CD}^{+}$and stem-like $\mathrm{CD}^{+}{ }^{+}$-cell proliferation in the LN. When the LN and the tumor were then targeted with RT, the abscopal effect was reduced, and we found a concomitant reduction in the number of total tumor-specific $\mathrm{CD}^{+} \mathrm{T}$-cells and stem-like $\mathrm{CD} 8^{+}$ T-cells in both the irradiated and unirradiated tumor. Conclusions These correlative results suggest the tumor-draining LN may be an important mediator of the abscopal effect by serving as a stem-like CD8 ${ }^{+} \mathrm{T}$-cell reservoir, a site for stem-like T-cell expansion, and a site from which they can populate the tumor.

\section{INTRODUCTION}

Although classically radiotherapy (RT) was only considered a local therapy, it occasionally led to tumor control outside the radiation field termed the 'abscopal effect'. 'The abscopal effect arises via stimulation of the antitumor immune response, particularly $\mathrm{CD}^{+}$T-cells. RT can, therefore, be considered a form of immunotherapy or in situ vaccination with resultant systemic effects. ${ }^{2-4}$ It increases major histocompatibility complex (MHC)-I expression ${ }^{5}$ and PD-L1 ${ }^{6}$ on tumor cells while promoting type I interferon (IFN) signaling via the cyclic GMP-AMP synthase (cGAS) and stimulator of interferon genes (STING) pathway in antigen-presenting cells. $^{7-9}$ Although the tumor is capable of T-cell priming and activation, ${ }^{10}$ lymph nodes (LN) are the classical sites for immune response generation. Tumor-draining LN have rich tumor drainage and are a site of high tumor antigen load. ${ }^{11}$ They are also important sites for dendritic cell mediated antitumor T-cell stimulation-a critical step in T-cell reinvigoration with $\alpha \mathrm{PD}-\mathrm{L} 1$. $^{12-14}$ The impact of nodal disruption with either surgery or tumor-draining LN-directed RT on local tumor growth following tumor irradiation has also been evaluated. Takeshima et $a l^{15}$ demonstrated reduced local tumor control in mice genetically deficient for LN (Aly/Aly) or with the LN surgically ablated. More recently, Marciscano et $a l^{16}$ showed that stereotactic irradiation of the tumor-draining LN leads to reduced local control and reduced tumor immune infiltrates. These data and observations suggest that the tumor-draining LN may also have an important role in an abscopal response.

Based on these preliminary observations, we investigated the impact of disrupting the tumor-draining LN on the abscopal effect. This is a critical question. If the tumor-draining 
LN is important in mediating the abscopal effect, patients treated with tumor and nodal irradiation or surgical LN removal who harbor undetected, distant micrometastatic disease may be compromising long-term survival if nodal disruption blunts an otherwise robust abscopal response.

Additionally, our lab has performed detailed studies of T-cell exhaustion, a phenomenon first reported in a chronic lymphocytic choriomeningitis virus (LCMV) infection. ${ }^{17-19}$ Using this system, disruption of the PD-1/PD-L1 interaction was shown to reinvigorate $\mathrm{CD}^{+}{ }^{\text {T-cells. }}{ }^{20}$ Our group has shown that the proliferative burst following $\alpha$ PD-L1 therapy of exhausted CD8 ${ }^{+}$ PD- $1^{+}$T-cells is provided by a distinct T-cell subset. ${ }^{21}$ This T-cell subset has a unique 'stem-like' phenotype. $\alpha$ PD-L1 therapy stimulates self-renewal and proliferation of this subset followed by differentiation into terminally differentiated effectors capable of cell killing. ${ }^{21}$ Understanding the impact of RT on stem-like CD8 ${ }^{+}$T-cells and terminally differentiated effectors in the context of the abscopal effect may allow for enhancement of anti-tumor immune responses and improved response rates with $\alpha \mathrm{PD}-1 / \mathrm{L} 1$.

\section{MATERIALS AND METHODS Mice and cell lines}

Female C57BL/ 6 mice aged 6-8 weeks were purchased from Jackson Laboratories. All mice were used in accordance with the Emory University Institutional Animal Care and Use Committee guidelines. Mice were sacrificed if they becamed sick, lethargic or had $>10 \%$ wt loss prior to tumor volume defined endpoint. The B16F10 cell line was obtained from American Type Culture Collection (ATCC). A B16F10 cell line expressing the glycoprotein (GP) of the LCMV Armstrong strain was generated by lentiviral transduction as described previously. ${ }^{22}$ Briefly, the codon-optimized GP was cloned into the bicistronic replication deficient lentiviral vector pLVX-IRES-ZsGreen1 (Takara) followed by production of lentiviral particles in 293 T cells (ATCC) and lentiviral transduction of B16F10 cells. A stable B16F10GP cell line was established by sorting B16F10 cells expressing high levels of the green fluorescent protein ZsGreen1 using a FACSAriaII (BD Biosciences) 2 weeks after transduction. The cell line was grown in Dulbecco's modified Eagle's medium (DMEM) supplemented with 10\% FBS, $100 \mathrm{U} /$ $\mathrm{mL}$ penicillin and $100 \mathrm{ug} / \mathrm{mL}$ streptomycin, $2 \mathrm{mM}$ glutamine. The cells were cultured at $37^{\circ} \mathrm{C}$ with $5 \% \mathrm{CO}_{2}$.

\section{In vivo tumor irradiation experiments}

$5 \times 10^{5}$ B16F10GP cells were injected into bilateral flanks subcutaneously on day 0 . After the tumor was palpable (10-12 days), mice were irradiated on one side with a Superflab bolus $(0.5 \mathrm{~cm}$ tissue equivalent material) placed over the tumor, and thereafter tumor measurements were taken as indicated. During radiation, mice were anesthetized with tribromoethanol. The dose to the tumor was 10 Gy using $320 \mathrm{kVp}$ photons at $10 \mathrm{~mA}$. To avoid scatter radiation, the light field was focused on the tumor with a 5-8 $\mathrm{mm}$ margin, and all other regions were shielded with lead.

For tumor-draining LN identification, the tumordraining LN was initially localized using a contrast microCT-scan as well as LN mapping. For the LN mapping, 5\% Evans Blue was injected intratumorally or into the right flank of a naïve mouse. Mice were sacrificed at $5 \mathrm{~min}$ and 30 min following injection, and at necropsy, blue $\mathrm{LN}$ were identified.

For tumor-draining LN irradiation, mice were set up clinically based on anatomic and CT-scan-guided landmarks. To minimize scatter to non-ipsilateral tumordraining LN sites, all regions including the ipsilateral tumor were lead shielded. To confirm minimal scatter to the ipsilateral tumor and the correct dose to the tumordraining LN, an optically stimulated luminescent dosimeter was implanted at both sites (Landauer, Glenwood, Illinois, USA). The prescribed dose to the tumor-draining $\mathrm{LN}$ were $3 \mathrm{~Gy}$ x three for a total of $9 \mathrm{~Gy}$ over 6 days. Mice were sacrificed according to the guidelines put forward by Emory University Institutional Animal Care and Use Committee.

For CD8 T-cell depletion, we injected $500 \mu \mathrm{g}$ of $\alpha \mathrm{CD} 8$ (Clone 2.43) injected IP on days 0, 7 and 14.

For FTY720 experiment, FTY720 (Sigma) was placed in drinking water $(2 \mu \mathrm{g} / \mathrm{mL}) 1$ day prior to tumor-directed RT (T-RT). FTY720 treatment was continued throughout the entire experimental course.

For T-cell analysis, mice were sacrificed on Day 17 when tumor, spleen and tumor-draining LN were harvested. $\mathrm{CD}^{+}{ }^{+}$T-cells were purified from tumors using a histopaque gradient (Sigma, St. Louis, MO). Tumors were weighed at time of sacrifice and recorded in grams. For cytokine staining, tumor infiltrating lymphocytes were cultured in RPMI $+10 \%$ FBS for 5 hours with an LCMV GP peptide pool in the presence of brefeldin A and monensin.

For tumor measurement, tumor diameters were assessed using calipers. Tumor volume was calculated using the formula for ellipse, that is, $4 / 3 \pi$.(l.w.h), where 1 , $\mathrm{w}$ and $\mathrm{h}$ represent the three diameters of the tumor taken perpendicular to each other.

Representative flow plots and tumor kinetics for figures 1, 4, 6-7 are taken from one experiment with all three experimental arms included. All experiments were done in duplicate or triplicate, and quantified data represent combined data unless otherwise noted.

\section{Flow cytometry}

Flow cytometric analysis was performed on an FACS Canto II or LSR II (BD Biosciences). Direct ex vivo staining and intracellular cytokine staining were performed as described previously ${ }^{23}$ with fluorochrome-conjugated antibodies (purchased from BD Bioscience, eBioscience, BioLegend, R\&D, Cell Signaling Technology, Vector Laboratories and Invitrogen). To detect tumor-specific $\mathrm{CD}^{+}$T-cell responses, MHC-I tetramers were prepared as described previously. ${ }^{24}$ For intracellular detection of transcription factors such as T-cell factor-1 (TCF-1), cells 
were surface stained for $45 \mathrm{~min}$ on ice, fixed and permeabilized using the Foxp3 Permeabilization/Fixation Kit according to manufacturer's instructions (eBioscience), followed by intracellular staining for $45 \mathrm{~min}$. All staining was performed in a 96 well plate using $1-5 \times 10^{6}$ total cells per well. Following staining, a minimum of $10^{4} \mathrm{CD} 8^{+}$ T-cells were collected by flow cytometer. Splenocytes were used for single color controls. TCF-1 gating was determined based on naïve $\mathrm{CD}^{+}$T-cell expression. Full gating strategy can be seen in (online supplemental figure 1). FACS data were analyzed with FlowJo software (TreeStar). The following antibodies were used: CD8a (Clone 53-6.7, BD), CD4 (Clone GK1.5, BD), CD44 (Clone IM7, BD), PD-1 (Clone 29F.1A12, Biolegend), IFN- $\gamma$ (Clone XMG1.2, Biolegend), IL-2 (Clone JES6-5H4, BD), TNF- $\alpha$ (Clone MP6-XT22, BD), TCF-1 (S33-966, BD), Tim-3 (Clone RMT3-23, Biolegend), GzmB (Clone GB11, BD), Ki-67 (Clone B56, BD), FoxP3 (Clone R16-715, BD).

\section{Statistics}

All experiments were analyzed using Prism 6 (GraphPad Software). Statistical differences were assessed using a Student's t-test or as detailed in the figure legend. P values of $<0.05$ were considered statistically significant $(*)$.

\section{RESULTS}

\section{The abscopal effect is induced by tumor-directed RT}

To assess whether tumor-directed RT (T-RT) alone can improve distant tumor control, we implanted syngeneic B16F10GP tumor cells into the bilateral flanks of immunocompetent mice. The use of the B16F10GP cell line expressing LCMV GP allows us to identify and track tumor-specific T-cells with MHC-I tetramers in various organs. In mice treated with T-RT, the tumor received 10 Gy x 1 with a $0.5 \mathrm{~cm}$ bolus to ensure appropriate surface dose (figure 1A). Following T-RT, we observed slowing of tumor growth of the irradiated (tumor 1) (figure 1B,C top) and a reproducible abscopal effect at the unirradiated site (tumor 2) (figure 1B C bottom). To characterize and quantify the intraumoral T-cell response, we evaluated

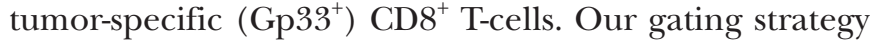
is shown in online supplemental figure 1 . There was an increase in the number of tumor-specific $\mathrm{CD}^{+} \mathrm{T}$-cells per gram in the unirradiated tumor (tumor 2) with a trend towards an increase in the irradiated tumor (Tumor 1) (figure 1D, online supplemental figure 2A). Increased proliferation of tumor-specific CD8 ${ }^{+}$T-cells in tumor 1 was also observed (figure 1D, right). Both tumor 1 and tumor 2 had an increased frequency and tumor 1 showed increased number with a trend for tumor 2 of IFN $\gamma^{+} \mathrm{CD} 8^{+}$ T-cells following T-RT (figure 1E, left, middle). There was also an increased frequency of polyfunctional CD8 ${ }^{+}$ T-cells in Tumor 2 (figure 1E, right) which represent a less exhausted T-cell subset. To verify that the observed effect was $\mathrm{CD}^{+}$T-cell dependent, we depleted $\mathrm{CD}^{+}$
T-cells prior to tumor irradiation (figure 2A,E). This significantly reduced the abscopal effect (figure 2B,C,D).

To determine whether this abscopal response is dependent on the strong antigen (Gp33), we performed the same experiment with the B16F10 parental line, and we observed improved local control with tumor irradiation, but no abscopal effect (online supplemental figure 2B) with minimal increase in the density of CD8+PD-1+T cells in the unirradiated tumor (online supplemental figure 2C).

We then performed a dose escalation experiment from 0, 10 and 20 Gy to assess whether increasing dose would increase the magnitude of the abscopal effect using B16F10GP tumors. We found that both 10 and $20 \mathrm{~Gy}$ had similar local control (figure 2F,G top) and distant control (figure 2F,G bottom). We also found a similar trend towards increased tumor-specific $\mathrm{CD}^{+} \mathrm{T}$-cells per gram in the 10 and $20 \mathrm{~Gy}$ groups with a trend towards a higher T-cell frequency in the 10 Gy cohort (figure $2 \mathrm{H}$ ).

\section{Stem-like CD8 ${ }^{+}$T-cells are found in the tumor and tumor- draining LN}

Next, we wished to characterize the tumor-specific T-cell population in the tumor and tumor-draining $\mathrm{LN}$ in more detail. We found that the majority $(>85 \%)$ of the ${\mathrm{Gp} 33^{+}}^{+}$ T-cells in the tumor were terminally differentiated effectors (figure 3A). Given the importance of stem-like $\mathrm{CD} 8^{+}$ T-cells $\left(\right.$ Tim- $3{ }^{-}$TCF- $1^{+}$) in response to $\alpha$ PD-L $1,{ }^{21}$ we next evaluated the stem-like CD8 ${ }^{+}$T-cell population in the tumor. After gating on the tumor-specific $\mathrm{CD} 8^{+} \mathrm{T}$-cells, we found $\mathrm{CD}^{+} \mathrm{T}$-cells with a stem-like phenotype in the tumor although at low frequencies (figure 3A, top). In the chronic LCMV infection, stem-like $\mathrm{CD} 8^{+} \mathrm{T}$-cells were found at greatest frequencies in secondary lymphoid organs, therefore, we next evaluated the tumor-draining $\mathrm{LN}$. In the LN, we found tumor-specific $\mathrm{CD}^{+} \mathrm{T}$-cells with intermediate expression levels of PD-1 (figure 3A, bottom left). After gating on the tumor-specific $\mathrm{CD} 8^{+} \mathrm{T}$-cells, we found that $>75 \%$ of these cells have a stem-like phenotype (figure 3A, bottom middle). We confirmed that the GzmB expression was much higher in the terminally differentiated effectors both in the tumor and LN than the stem-like CD8 ${ }^{+}$T-cells as has been shown previously ${ }^{21}$ (figure 3A, right). Finally, we quantified the frequency differences between the stem-like $\mathrm{CD} 8^{+} \mathrm{T}$-cells in both the $\mathrm{LN}$ and tumor and the terminally differentiated effectors (figure 3B). These data clearly show that the frequency of stem-like $\mathrm{CD}^{+} \mathrm{T}$-cells is dramatically higher in the $\mathrm{LN}$ than the tumor. A similar difference in stem-like T-cell frequency between the tumor and $\mathrm{LN}$ was observed in the parental B16F10 cell line (online supplemental figure 2D).

\section{The impact of tumor RT on T-cells subsets in the tumor and LN}

Next, we evaluate the impact of tumor irradiation on the T-cell subsets in both the tumor and the tumor-draining LN. We found that T-RT increased the number of 
A

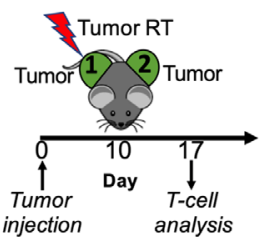

B

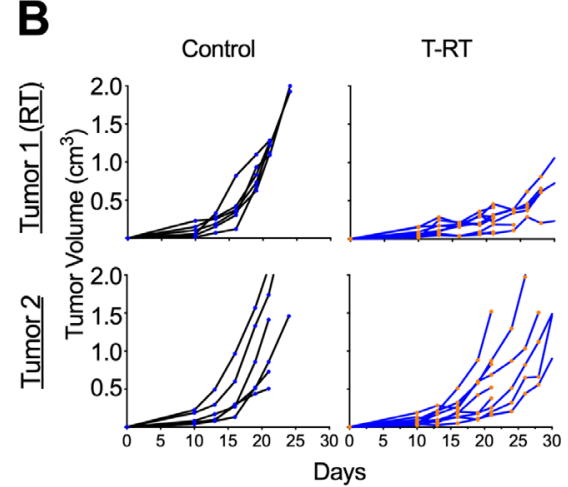

$\mathbf{C}=\underset{\mathrm{T}-\mathrm{R} T}{\text { Control }}$

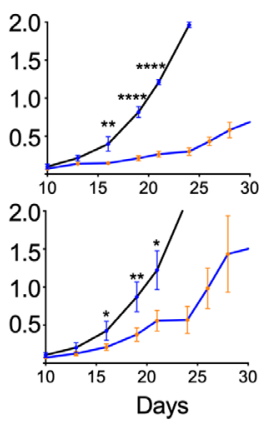

D Antigen-specific CD8 ${ }^{+} T$-cell response in the tumor (gated on $C D 8^{+}$).
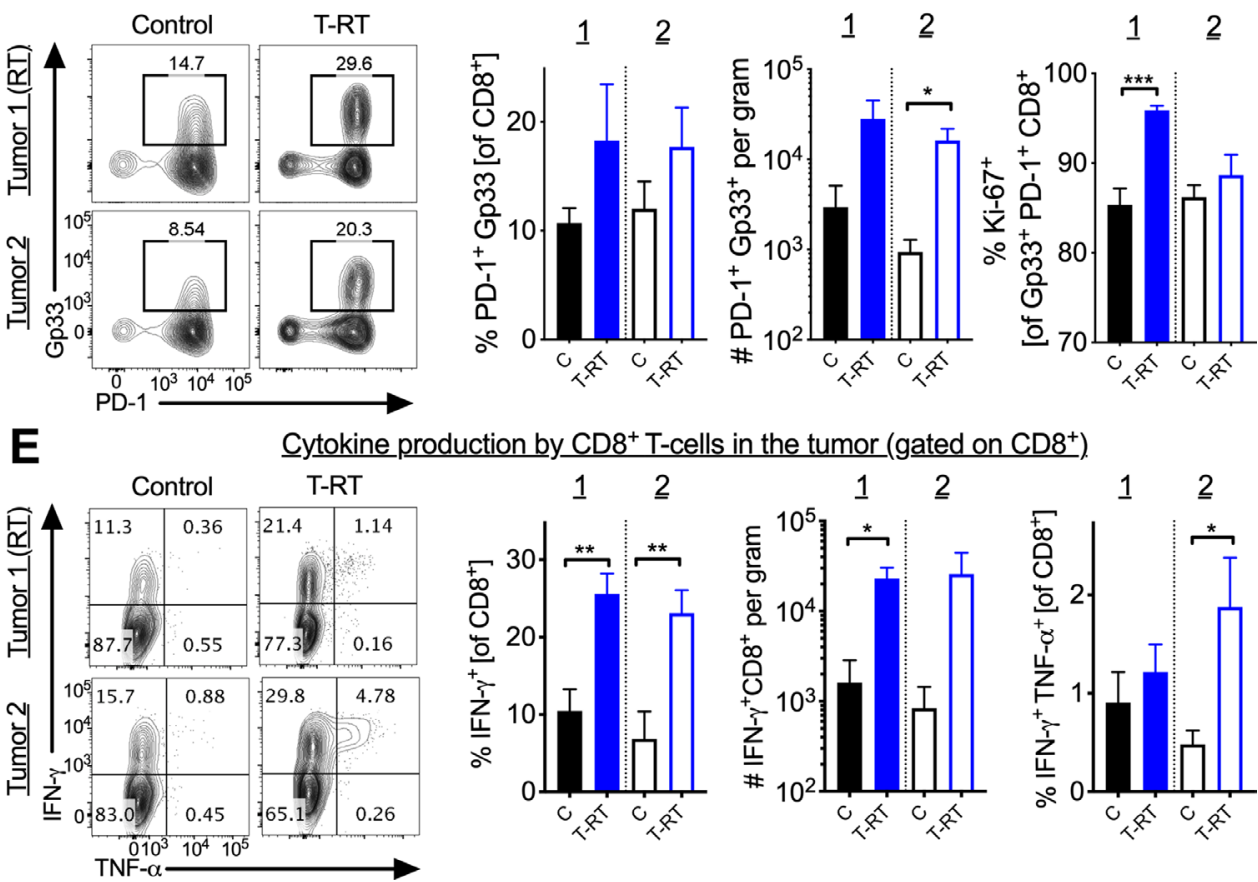

Figure 1 The abscopal effect is induced by tumor-directed radiotherapy (RT). (A) Schema for tumor-directed RT administration. (B) Tumor growth curves demonstrating an abscopal effect in tumor 2. Tumors were measured at indicated time points. Experiment repeated three times with 4-8 mice per group with curves from a representative experiment. For additional clarity, the tumor side that is irradiated is denoted with (RT). (C) Mean tumor growth curves with $\mathrm{SEM}$. ${ }^{*} \mathrm{P}<0.05$, ${ }^{\star \star \star} \mathrm{P}<0.001,{ }^{\star \star \star \star} \mathrm{P}<0.0001, \mathrm{p}$ values calculated using two-way ANOVA with Sidak's multiple comparison. $\mathrm{Y}$-axis same as in (B). (D) Control and T-RT mice were sacrificed on day 17 (7 days post-RT). Left, representative flow cytometry plots gated on CD8 ${ }^{+}$ T-cells. The boxed population represent PD $-1^{+} \mathrm{Gp} 33^{+}$(immunodominant epitope of the inserted LCMV GP). Right, quantified frequency of PD $-1^{+} \mathrm{Gp} 33^{+}$of $\mathrm{CD} 8^{+}$, number of PD- $1^{+} \mathrm{Gp} 33^{+} \mathrm{CD} 8^{+}$per gram, and frequency of Ki- $67^{+}$of PD- $1^{+} \mathrm{Gp} 33^{+}$. (E) Left, representative flow plots gated on $\mathrm{CD} 8^{+} \mathrm{T}$-cells following 5 hours of peptide restimulation ex vivo. Right, quantified numbers and frequencies of cytokine positive CD8 ${ }^{+} T$-cells. Error bars represent SEM, ${ }^{*} \mathrm{p}<0.05,{ }^{* *} \mathrm{p}<0.01,{ }^{* \star *} \mathrm{p}<0.001$. $(\mathrm{C}=\mathrm{control}$, unirradiated mice). Experiments were repeated three times with 4-8 mice per group. ANOVA, analysis of variance; GP, glycoprotein; IFN $\gamma$, interferon- $\gamma$; LCMV, lymphocytic choriomeningitis virus; TNF $\alpha$, tumor necrosis factor- $\alpha$; T-RT, tumor-directed RT.

stem-like CD8 ${ }^{+}$T-cells, but not their frequency in tumor 1 with a similar trend for tumor 2 and for terminal effectors (figure $4 \mathrm{~A}$ ). In the parental B16F10 cell line, no significant increase in stem-like $\mathrm{CD} 8^{+} \mathrm{T}$-cells was observed following T-RT in tumor 1 or 2 (data not shown).

We found no statistically significant or trends in changes in the frequency of stem-like or terminal effectors in the LN 7 days following T-RT (figure 4B). We did, however, see an increase in the frequency of proliferating tumorspecific $\mathrm{CD}^{+}$T-cells (figure 4C, left and middle), stemlike $\mathrm{CD}^{+} \mathrm{T}$-cells (figure 4C, right) and a more modest increase in terminal effectors (online supplemental figure $2 \mathrm{E}$ ). As this proliferative response suggests the $\mathrm{LN}$ may play a role in the abscopal effect, we next focused our attention on the LN.

\section{Tumor-draining LN directed RT is feasible}

To evaluate the importance of the tumor-draining LN in mediating the abscopal effect, we depleted tumordraining LN lymphocytes by targeted RT (LN-RT). To first confirm that we were able to identify the first echelon tumor-draining LN anatomically, we injected Evans Blue 

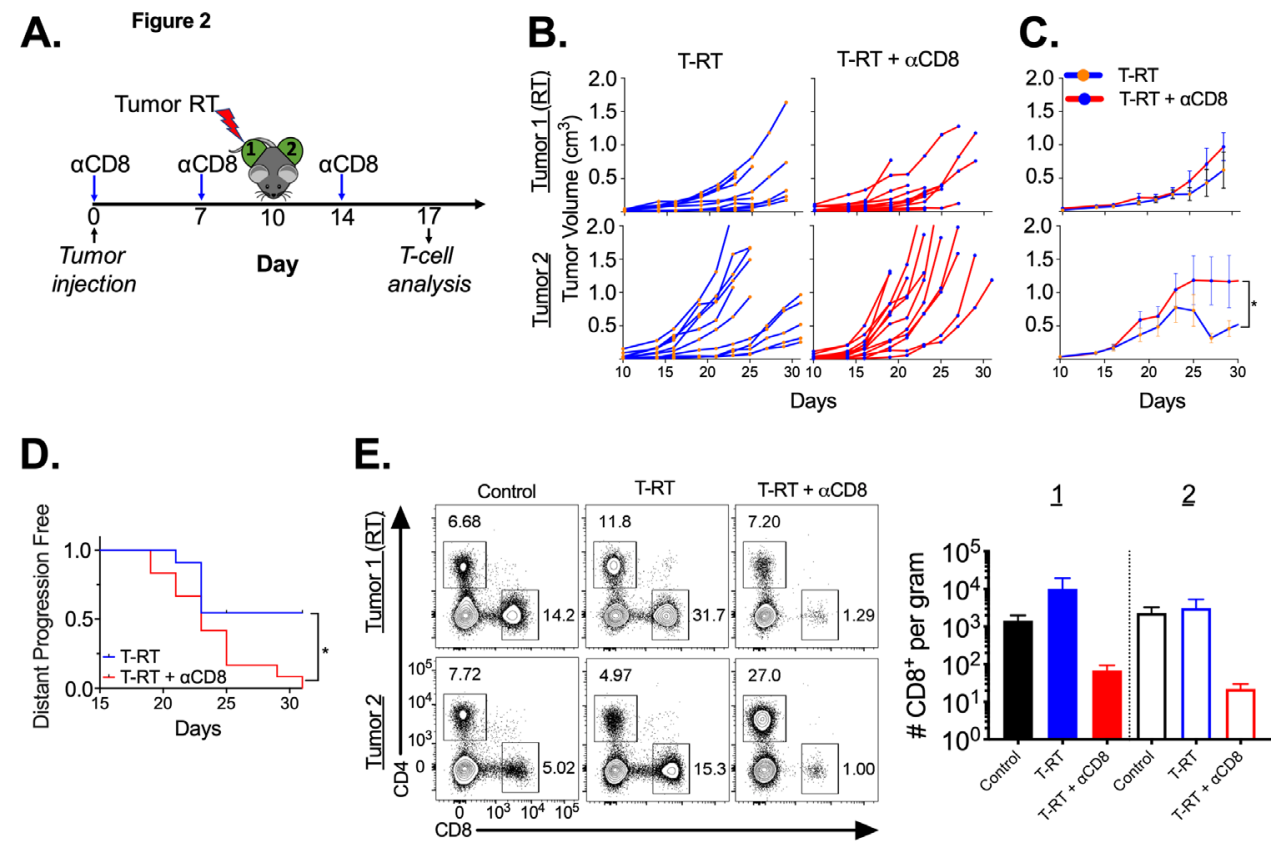

F.

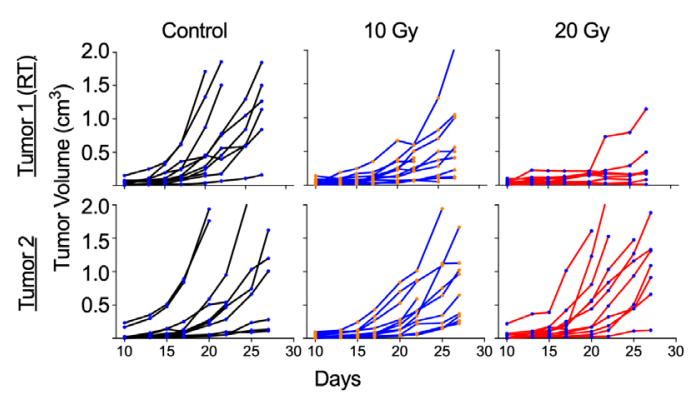

G.
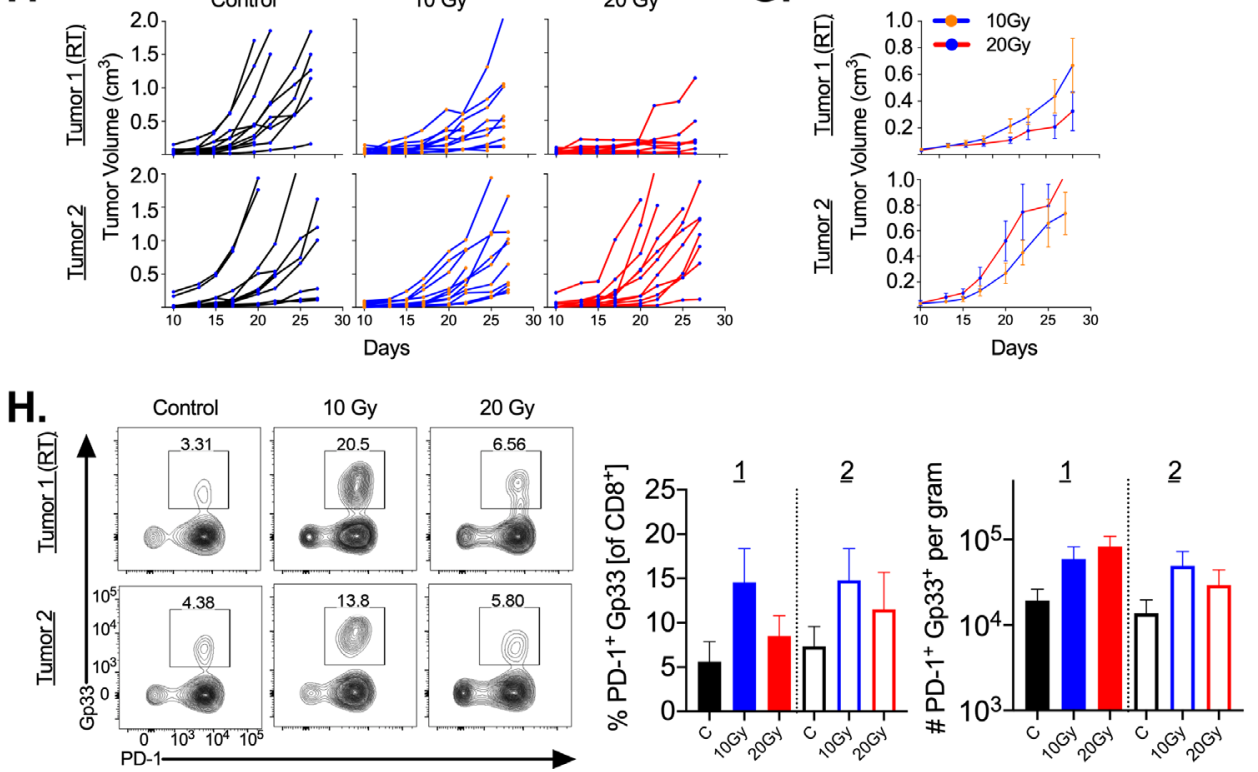

Figure 2 .Abscopal effect is dependent on $\mathrm{CD}^{+} \mathrm{T}$-cells. (A) Schema for tumor-directed RT administration with timing of $\alpha \mathrm{CD} 8$ depleting antibody. (B) Tumor growth curves demonstrating a significant reduction in the abscopal effect in tumor two with $C D 8^{+} T$-cell depletion. Tumors were measured at indicated time points. (C) Mean tumor growth curves with SEM, $y$-axis as in $B .{ }^{*} P<0.05$. (D) Kaplan-Meier plot with event defined as the abscopal tumor (tumor 2) reaching $1000 \mathrm{cc}$ (defined as distant progression). ${ }^{*} \mathrm{P}<0.05$, $p$ value calculated using log-rank test. (E) Mice were sacrificed on day 17 (7 days post-RT). Left, representative flow cytometry plots gated on live lymphocytes in tumor. Right, quantitation demonstrating CD8 ${ }^{+} \mathrm{T}$-cell depletion in the tumor. (F) Dose escalation of tumor-directed RT with same schema as in figure 1A. (G) Mean tumor growth curves with

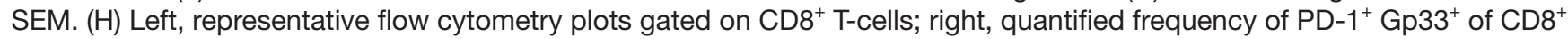
and number of PD- $1^{+} \mathrm{Gp} 33^{+} \mathrm{CD} 8^{+}$per gram tumor. T-RT, tumor-directed RT.

at the site of flank tumor inoculation and sacrificed the mice at $5 \mathrm{~min}$ postinjection. At that time, the only LN that demonstrated visible uptake of the dye was the ipsilateral inguinal node (figure 5A). To confirm that this node could be accurately targeted with kilovoltage $\mathrm{X}$-rays, we acquired a contrasted micro CT (figure 5B) and performed dosimetric calculations based on planned field size, and depth of the inguinal nodal basin. We then confirmed prescribed dose delivery by dosimeter implantation at the LN site and tumor site demonstrating minimal scatter to the tumor with appropriate shielding (not shown). As a further confirmation, we evaluated for lymphocyte death in the targeted node following RT by sacrificing mice 36 hours after the first RT fraction (figure $5 \mathrm{C}$ ) and performing Annexin- $\mathrm{V}$ and 7-AAD staining (figure 5D). We observed increased cell death in 
A

B
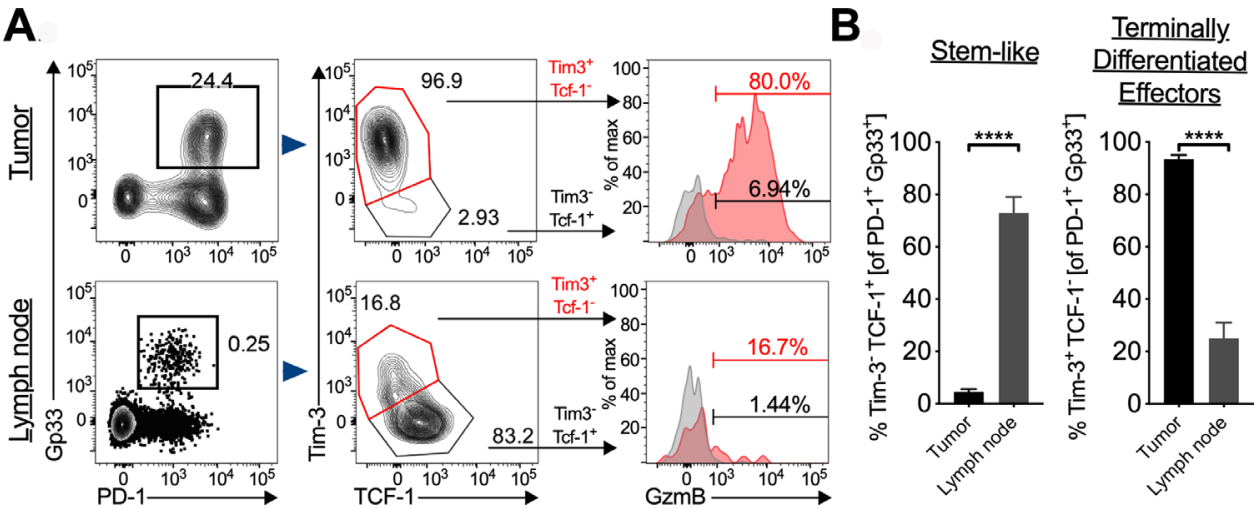

Figure 3 Stem-like T-cells in the tumor and tumor-draining lymph node (LN). (A) Left, representative flow plots of T-cells gated on PD- $1^{+} \mathrm{Gp} 33^{+}$in the tumor; middle, stem-like $\mathrm{CD} 8^{+}$T-cells gated on PD $-1^{+} \mathrm{Gp} 33^{+}$in the tumor; right, representative histogram of $\mathrm{GzmB}^{+}$of each subset in the tumor and LN. (B) Quantification of frequency of stem-like CD8 ${ }^{+} \mathrm{T}$-cells and terminally differentiated effectors in both the tumor and LN. Error bars represent SEM, ${ }^{* \star * *} \mathrm{p}<0.0001$.

the irradiated node (figure 5D). To confirm that there was actual depletion of T-cells from the targeted tumordraining LN, mice were sacrificed on day 7 following 3 Gy x 3 fractions to the CT-assessed location. Fractionated LN-RT was selected after 10 Gy x 1 showed no depletion of lymphocytes in the irradiated LN at day 7 post-RT (data not shown). This was likely due to rapid LN repopulation from the blood. The inguinal LN in the prescribed radiation field demonstrated a consistent two log decrease in the number of $\mathrm{CD}^{+}$and $\mathrm{CD}^{+} \mathrm{T}$-cells (figure $5 \mathrm{E}$ ). No concomitant decrease in the number of splenic lymphocytes was observed (figure 5F) demonstrating that the radiation is specifically targeting the $\mathrm{LN}$ and not causing a global decrease in the circulating lymphocyte population. We next performed a time course and found the nadir of the LN T-cells was at day 10 following the first radiation fraction (figure 5G). However, day 7 was selected for sacrifice as there was a significant decrease in LN cell numbers at this time point and it represented the apex of the T-cell infiltration into the tumor.

\section{Tumor-draining LN directed $\mathrm{RT}$ reduces the abscopal effect}

Next, we evaluated the impact of LN irradiation on tumor growth. We irradiated both the tumor-draining LN of tumor 1 with fractionated RT (3 Gy x 3 fractions) and tumor 1 with the single $10 \mathrm{~Gy}$ dose (figure 6). Irradiating the tumor-draining LN and the tumor (T-RT+LN RT) did not significantly impair local tumor control (figure 6B,C top), however, there was a reduction in the abscopal effect (figure 6B,C bottom).

For T-cell analysis, mice were sacrificed 1 day following the last fraction of tumor-draining LN-directed RT (day 17) (figure 6A). The increase in tumor-specific $\mathrm{CD}^{+}$T-cells seen in tumor 2 (unirradiated tumor) with tumor 1-directed RT was decreased in the T-RT+LN RT group (figure $6 \mathrm{D}$, right). Tumor-draining $\mathrm{LN}$-directed RT also reduced the frequency of proliferating tumorspecific $\mathrm{CD}^{+}$T-cells in the irradiated tumor (Tumor 1) (figure 6D, bottom). Frequencies of both $\mathrm{IFN}_{-} \gamma^{+} \mathrm{CD} 8^{+}$ T-cells and IFN- $\gamma^{+}$TNF- $\alpha^{+} \mathrm{CD} 8^{+}$T-cells were reduced in tumor 2 in the T-RT+LN RT compared with the T-RT group (figure $6 \mathrm{E}$ ).

\section{Tumor-draining LN RT decreases the number of stem-like $\mathrm{CD}^{+}{ }^{+} \mathrm{T}$-cells in the tumor}

We next evaluated whether tumor-draining LN-directed RT reduced the stem-like $\mathrm{CD} 8^{+} \mathrm{T}$-cell numbers in the LN. We found a significant decrease in the T-RT+LN RT group in the irradiated (tumor 1 side) as well as the un-irradiated (tumor 2 side) tumor-draining LN (figure 7A, left). The magnitude of the decrease was much greater in the irradiated compared with the unirradiated tumordraining LN. Next, we looked in the tumor and found that in both tumor 1 and tumor 2 of the T-RT+LN RT group there was a reduction in stem-like $\mathrm{CD} 8^{+} \mathrm{T}$-cell numbers relative to the T-RT group (figure $7 \mathrm{~B}$, left). There was similar trend towards a reduction for terminally differentiated effectors in Tumor 1, but not for tumor 2 (figure 7B, right). No significant difference was observed in the frequency of tumor-infiltrating regulatory T-cells with T-RT or T-RT+LN RT in either tumor 1 or tumor 2 (online supplemental figure $2 \mathrm{~F}$ ).

To further confirm the importance of the $\mathrm{LN}$ in the abscopal response, mice were treated with FTY720, which sequesters lymphocytes in secondary lymphoid tissue, prior to T-RT (online supplemental figure 3A,B). A significant decrease in the abscopal effect at tumor 2 was observed with T-RT+FTY720 (online supplemental figure 3C,D bottom) relative to T-RT alone.

\section{DISCUSSION}

It has been shown that RT is immunogenic, in part, by stimulating de novo T-cell priming via neo-antigen liberation, ${ }^{25} 26$ and can synergize with checkpoint blockade to improve local as well as distant tumor control. ${ }^{27} 28$ It has also been demonstrated that tumors themselves can act as a site of T-cell priming and activation. ${ }^{10}$ We confirmed that T-RT stimulated an antitumor immune response in our system and improved distant tumor control 
A $\quad$ CD8 $8^{+} \mathrm{T}$-cell subsets in the tumor (gated on $\mathrm{G} p 33^{+} \mathrm{CD} 8^{+}$).
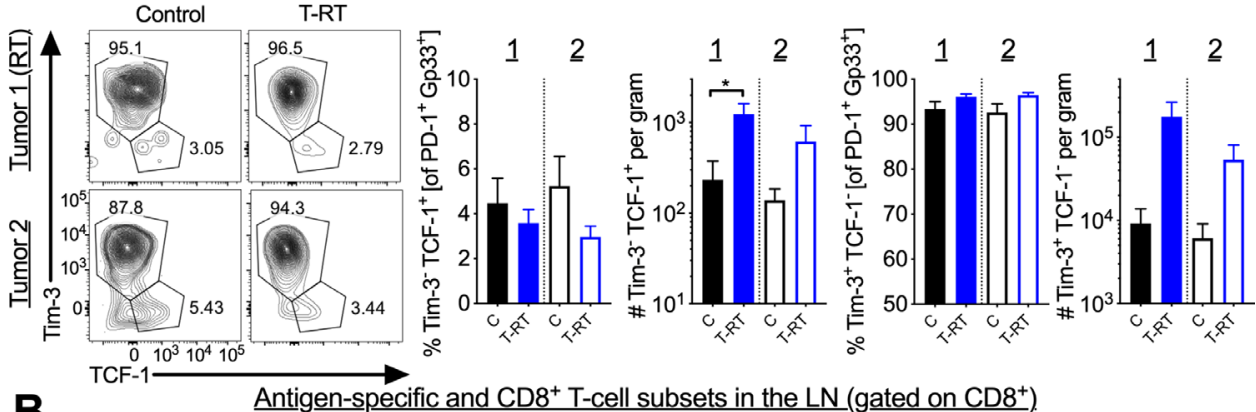

B
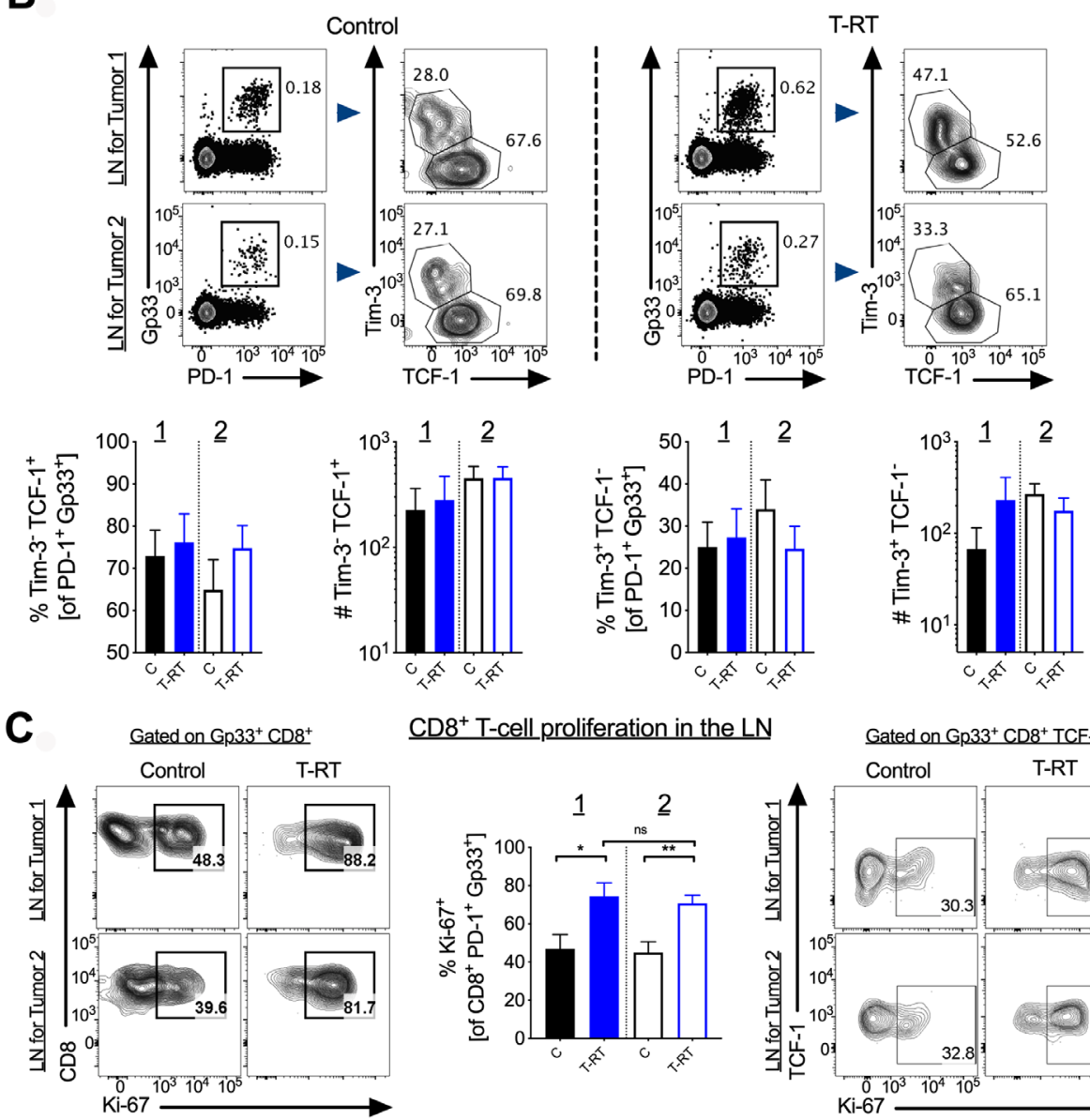

$\mathrm{CD}^{+} \mathrm{T}$-cell proliferation in the $\mathrm{LN}$
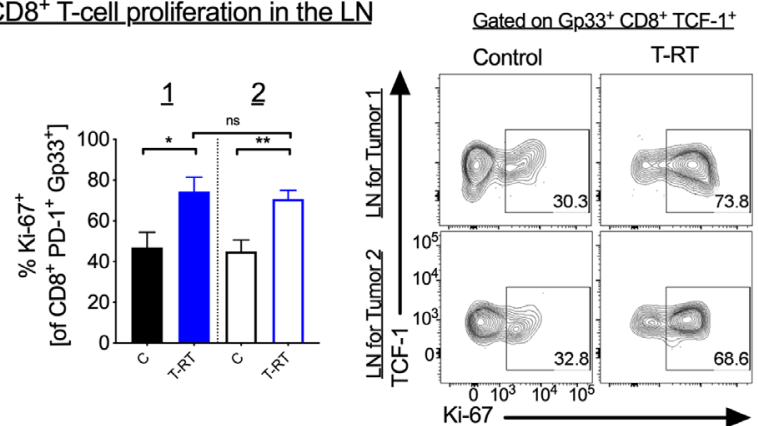

Figure 4 Tumor-directed RT induces proliferation of T-cells in tumor-draining lymph node (LN). (A) Left, representative flow plots of stem-like CD8 ${ }^{+} \mathrm{T}$-cells gated on $\mathrm{PD}-1^{+} \mathrm{Gp} 33^{+}$in the tumor. Right, quantification of frequency and number per gram of the Tim $-3^{-} \mathrm{TCF}-1^{+}$subset, and Tim $-3^{+} \mathrm{TCF}-1^{-}$. (B) Top, representative flow plots of PD- $1^{\text {int }}$ Gp $33^{+}$in the tumor-draining $\mathrm{LN}$ gated on $\mathrm{CD}^{+}$T-cells. Bottom, quantification of the frequency and numbers of PD- $1^{\text {int }}$ Gp33 $3^{+}$T-cell subsets in the tumordraining LN. (C) Left, representative flow plots of proliferating $\left(\mathrm{Ki}-67^{+}\right)$tumor-specific $\mathrm{CD} 8^{+} \mathrm{T}$-cells gated on PD- $1^{\text {int }} \mathrm{Gp3} 33^{+}$in the tumor-draining LN. Middle, quantification of Ki-67+ frequency in the LN on the irradiated side (1) and unirradiated side (2). Right, representative flow plots of proliferating tumor-specific stem-like CD8 ${ }^{+}$T-cells gated on PD- $1^{\text {int }}$ Gp $33^{+}$TCF- $1^{+}$. Error bars represent $\mathrm{SEM},{ }^{*} \mathrm{p}<0.05$, ${ }^{* *} \mathrm{p}<0.01$. ns, not significant; T-RT, tumor-directed radiotherapy.

(figure 1B-D). We next investigated the importance of the tumor-draining $\mathrm{LN}$ in this effect, and found that T-RT+LN RT reduced the abscopal effect (figure 6B,C). This was further confirmed by treatment with FTY720 with T-RT (online supplemental file 3). As noted earlier, stem-like $\mathrm{CD}^{+} \mathrm{T}$ cells differentiate into terminally differentiated effectors, which have the potential for tumor-cell killing following $\alpha$ PD-L1 treatment. ${ }^{21}$ We hypothesized that the stem-like $\mathrm{CD}^{+}{ }^{+}$T-cells and terminally differentiated effectors in the tumor are supplied by the tumor-draining LN stem-like $\mathrm{CD} 8^{+}$T-cells due to their high frequency (figure 3A,B). We found that T-RT increased the stemlike T-cells in the distant tumor, but this was reduced by LN-RT (figure 7B). This observation is correlative, but does support our hypothesis. Interestingly, we also noted robust proliferation of tumor-specific $\mathrm{CD}^{+}{ }^{+} \mathrm{T}$-cells in the bilateral tumor-draining LN following T-RT (figure 4C) to one tumor suggesting the contralateral tumor-draining 
A

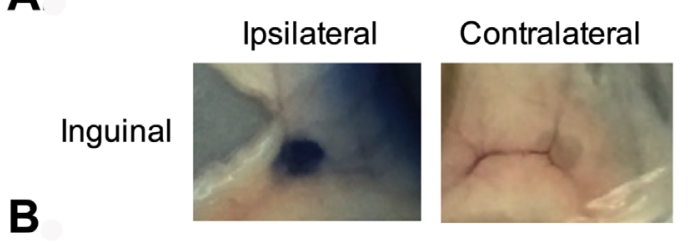

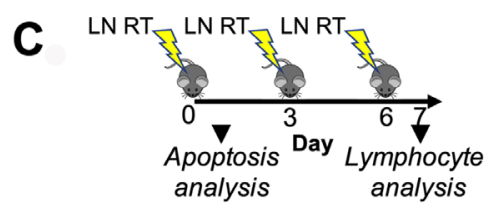

D 36 hours post-RT (gated on lymphocytes)

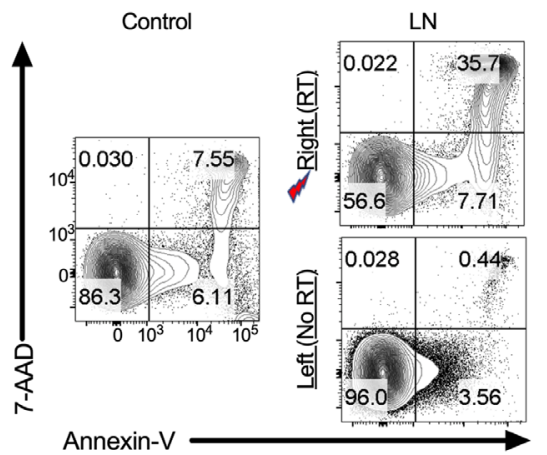

Annexin- $V$
E
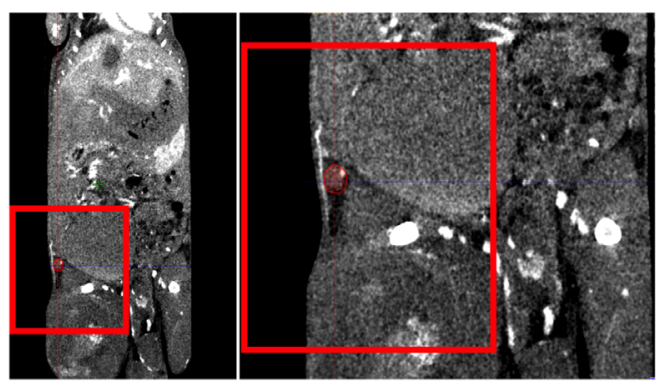

G
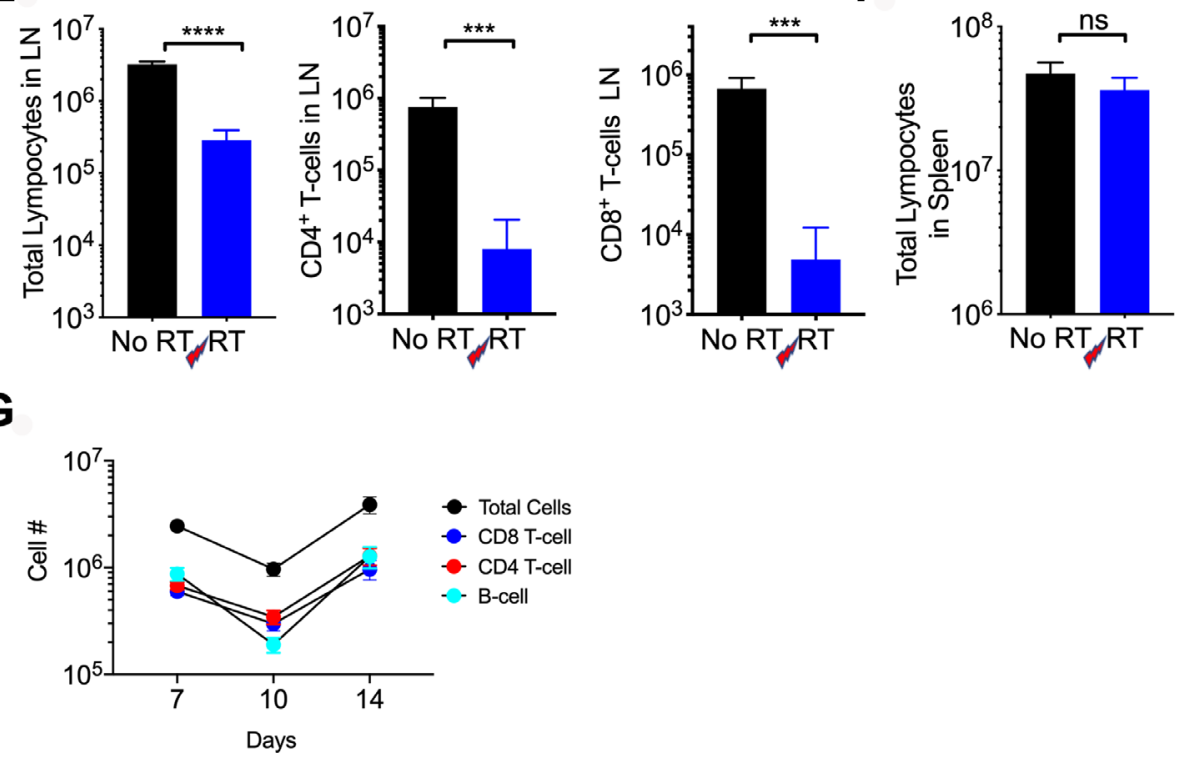

Figure 5 Accurate identification and targeting of the draining lymph node (LN) with fractionated radiotherapy (RT). (A) Top, Evans blue was injected in the left flank of C57BL/6 mice and 5 min later mice were sacrificed and blue inguinal LN were identified. (B) A micro-CT with contrast was obtained and the draining inguinal LN was identified and contoured in red. Red box represents radiation field borders. On right is a zoomed-in view of the targeted region. (C) Schema of administration of LN directed radiation. (D) 3 Gy was administered to the inguinal LN, 36 hours later cells were stained with Annexin-V ( $x$-axis) and 7-AAD (y-axis). Flow plots shown are gated on all lymphocytes. The control refers to a naïve, unirradiated mouse. (E) Following 3 fractions of $3 \mathrm{~Gy}$, mice sacrificed on day 7 showed a reduction in the number of total lymphocytes, $\mathrm{CD} 4^{+}$and $\mathrm{CD} 8^{+} \mathrm{T}$-cells in the irradiated LN. (F) No difference was seen in total splenic lymphocytes in mice with or without LN irradiation. Experiments were repeated twice with 3-4 mice per group. Error bars represent SEM, ${ }^{\star \star \star} p<0.001,{ }^{\star \star \star *} p<0.0001$. (G) Time course reflecting major lymphocyte subsets in the targeted LN; day 7 reflects 7 days from first RT dose or 1 day from final of three fractions. (E) No RT=tumor free mice without irradiation, $\mathrm{RT}=$ tumor free mice receiving $\mathrm{LN}$ directed radiation). ns, not significant.

LN may also be important in the abscopal effect. This may be due to either antigen liberated following tumor irradiation or antigen presenting cells in the tumor trafficking to both the ipsilateral and contralateral nodes to enhance tumor control. Alternatively, T-cells primed/reinvigorated in the ipsilateral tumor-draining $\mathrm{LN}$ may also circulate to the contralateral node to help with tumor control. A third possibility is that $\mathrm{CD}^{+}$T-cells activated in the ipsilateral LN traffic to the contralateral tumor (tumor 2), liberate tumor antigen which drains to Tumor 2's tumordraining LN and stimulates T-cell proliferation.

The role of the tumor-draining $\mathrm{LN}$ in anti-tumor T-cell activation has been evaluated by other groups who demonstrated reduced local control following either tumor-draining LN irradiation, genetic deficiency (Aly/ Aly) or surgical disruption. ${ }^{151616}$ We found that tumordraining LN irradiation blunted distant tumor control (figure 6B,C bottom). Interestingly, the tumor-draining 

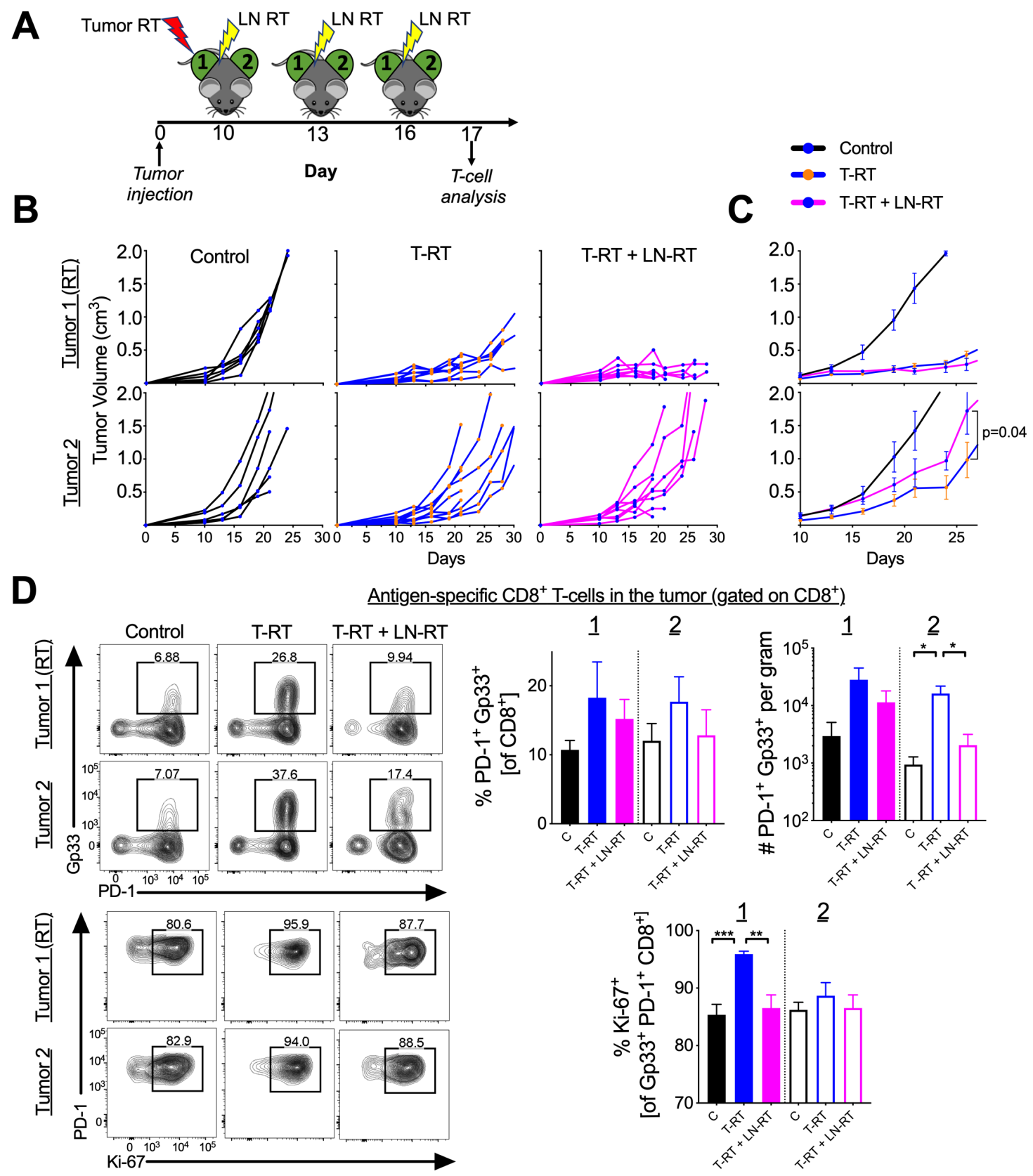

$\mathbf{E}$
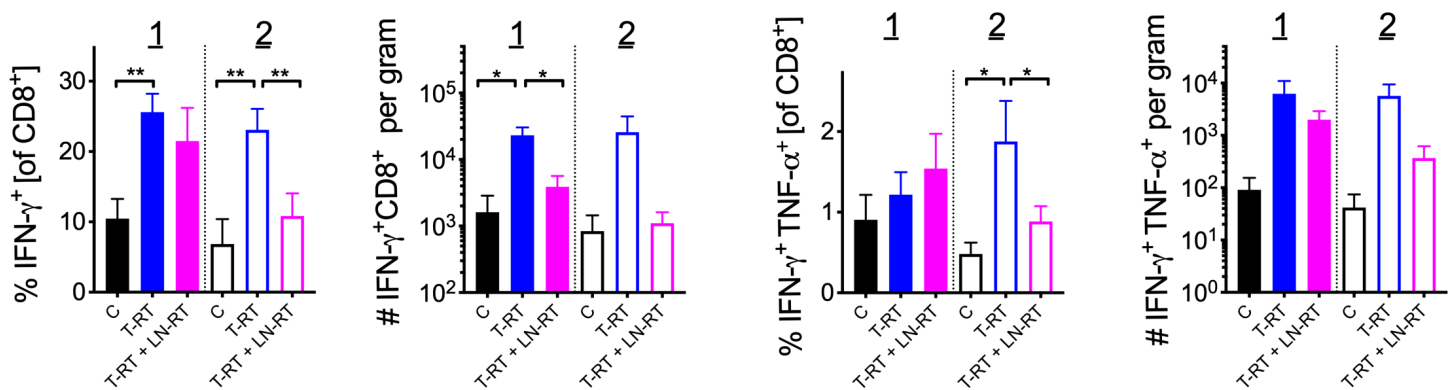

Figure 6 Tumor-draining lymph node (LN) directed irradiation reduces the abscopal effect. (A) Top, schema for tumor-directed RT and tumor-draining LN-directed RT. (B) Tumor growth curves demonstrating a reduction in the abscopal effect (tumor 2) with tumor-draining LN-directed RT. (C) Mean tumor growth curves with SEM, $y$-axis as in $B$. ${ }^{*} P<0.05$, $p$ values calculated using twoway ANOVA with Sidak's multiple comparison comparing T-RT and T-RT+LN-RT. (D) Quantification of frequency and number of tumor-specific CD8 ${ }^{+} \mathrm{T}$-cells and frequency of proliferating cells. (E) Quantified numbers and frequencies of cytokine positive $\mathrm{CD}^{+} \mathrm{T}$-cells following peptide pool restimulation. Error bars represent $\mathrm{SEM},{ }^{*} \mathrm{p}<0.05,{ }^{* *} \mathrm{p}<0.01,{ }^{* \star *} \mathrm{p}<0.001$. ANOVA, analysis of variance; IFN $\gamma$, interferon- $\gamma$; T-RT, tumor-directed radiotherapy; TNF $\alpha$, tumor necrosis factor- $\alpha$. 
A

Antigen-specific CD8 ${ }^{+}$T-cell subsets in the LN (gated on $\mathrm{CD}^{+}$).
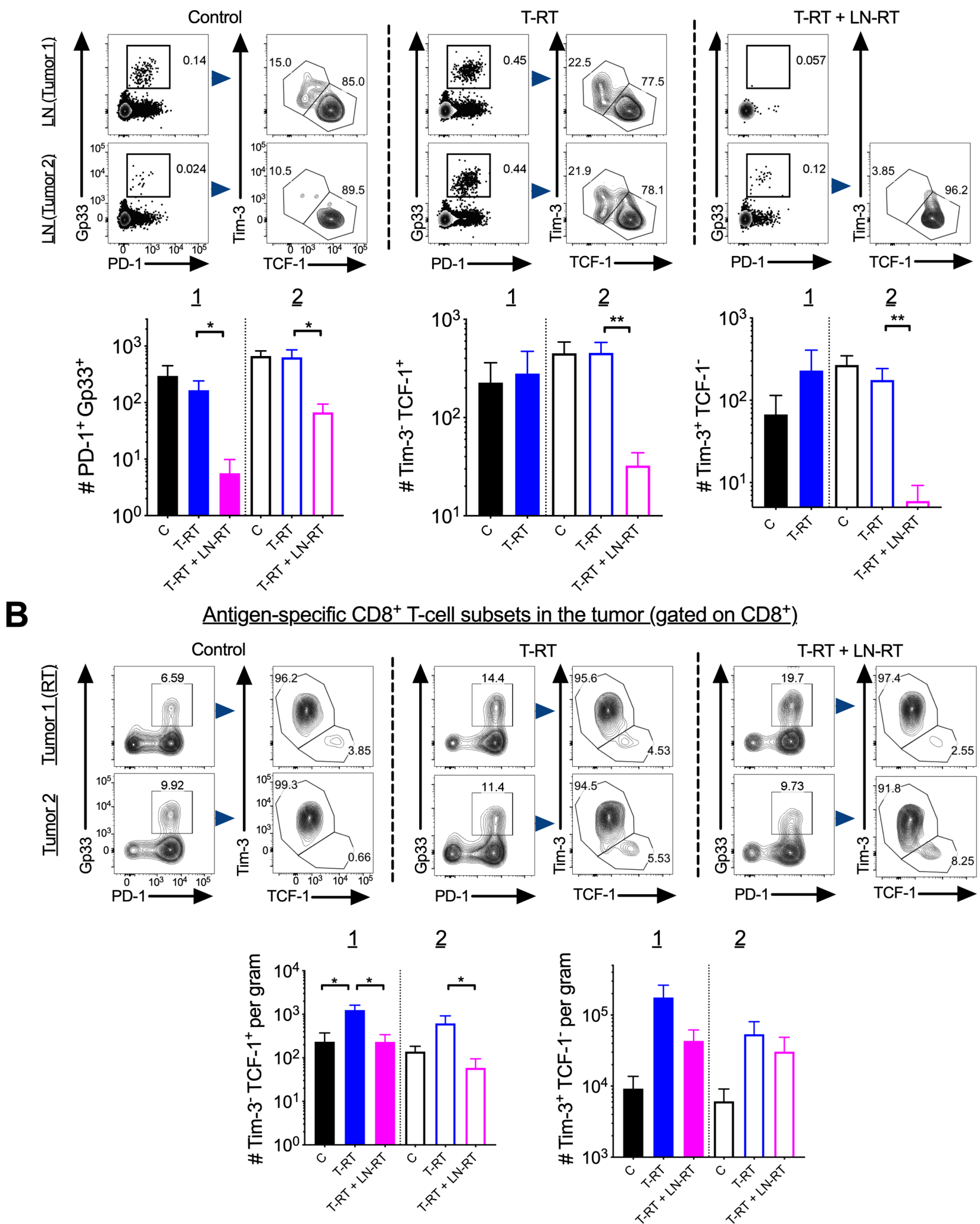

Figure 7 Tumor-draining lymph node (LN) irradiation decreases the number of stem-like CD8 ${ }^{+} \mathrm{T}$ cells. (A) Top, representative flow plots of PD- $1^{\text {int }} \mathrm{Gp} 33^{+}$in the tumor-draining LN gated on CD8 ${ }^{+}$T-cells. Bottom, quantification of the numbers of PD- $1^{\text {int }}$ Gp33 ${ }^{+}$T-cells in the tumor-draining LN; quantification of the number of stem-like CD8 ${ }^{+}$T-cells and terminally differentiated effectors in the tumor-draining LN. Population of stem-like T-cells from tumor-draining LN from Tumor 1 in the T-RT+LN-RT group not shown as there is no Gp33 ${ }^{+}$population on which to gate. Error bars represent $S E M,{ }^{*} p<0.05,{ }^{\star *} p<0.01$. (B) Top, representative flow plots of stem-like CD8 ${ }^{+} \mathrm{T}$-cells gated on PD- $1^{+} \mathrm{Gp} 33^{+}$in the tumor. Bottom, quantification of number per gram of the Tim- $-3^{-}$TCF $-1^{+}$subset, and Tim- $3^{+}$TCF-1 ${ }^{-}$. T-RT, tumor-directed radiotherapy. 
LN-directed RT without checkpoint blockade did not significantly reduce local control in contrast to these earlier reports. This may be because of shortened experiment length due to the limitations imposed by distant tumor size or variations in tumor cell line radiosensitivity. It may also be due to the highly immunogenic cell line we developed utilizing the LCMV GP. Finally, it may be due to the dose of 10 Gy used. Vanpouille-Box et $a l^{89}$ have shown that doses from 12 to 18 Gy induce TREX1, an exonuclease, which attenuates radiation's immunogenicity. The dose we selected may also explain why we observe a modest, but reproducible abscopal effect following tumor irradiation in the absence of concurrent checkpoint blockade.

Although our data do not formally confirm the following model, we propose that tumor-specific stemlike $\mathrm{CD}^{+}$T-cells in the tumor-draining $\mathrm{LN}$ provide a reservoir for the terminally differentiated effectors in the tumor which are capable of tumor cell killing; and stem-like $\mathrm{CD}^{+}$T-cell expansion in the tumor-draining $\mathrm{LN}$ and potentially migration to the tumor is stimulated by RT. An important question is whether the stem-like $\mathrm{CD}^{+}$within the tumor and tumor-draining $\mathrm{LN}$ are both capable of producing terminally differentiated effectors, and whether the quality of the terminally differentiated effectors may be different between the two. The tumorresident stem-like $\mathrm{CD}^{+}{ }^{+} \mathrm{T}$-cells may be more exhausted and produce suboptimal terminally differentiated effectors. To further evaluate these findings, future adoptive transfer, RNA-seq and conditional knock-out experiments are planned. The results presented here, however, correlative, are intriguing. They build on the result of multiple groups who have shown that the tumor-draining LN is the main site for exhausted T-cell proliferation following $\alpha \mathrm{PD}-1$ treatment. ${ }^{29}{ }^{30}$ Additionally, although this study's generalizability may be somewhat limited due the immunogenic, modified cell line used, human tumors show a wide range of immunogenicity. We contend that our model may reflect one end of this tumor spectrum and helps elucidate RT's immuno-stimulatory effects in that context.

Our findings have significant clinical implications for anticancer regimens which incorporate both primary tumor, nodal irradiation and immunotherapy for improved local control, especially in patients who are at high risk for distant disease failure. Multiple clinical trials are investigating the impact of stereotactic body radiotherapy and $\alpha \mathrm{PD}-1 / \mathrm{L} 1$ on an abscopal response in oligometastatic disease. ${ }^{31}$ However, it is relatively recent that immunotherapy has moved into the stage III setting. In melanoma, there is demonstrated improved recurrence free survival when pembrolizumab ( $\alpha \mathrm{PD}-1)$ is administered adjuvantly, ${ }^{32}$ with similar results for other checkpoint agents. ${ }^{33} 34$ The landmark PACIFIC Trial which showed an overall survival benefit for adjuvant durvalumab $(\alpha$ PD-L1) following definitive chemoradiation for Stage III non-small cell lung cancer is one of the first trials to incorporate both radiation and checkpoint blockade in the stage III setting. ${ }^{35}$ Despite a reduced frequency of new lesions, there was still a very high incidence in the durvalumab arm. It is the high distant failure, that may be improved with avoidance of LN irradiation when co-administered with $\alpha$ PD-L1 therapy.

In humans, studies in both melanoma and breast cancer have shown that immediate complete LN dissection, despite sentinel node involvement, did not provide an overall survival benefit. ${ }^{36-38}$ In fact, in the case of the Multicenter Selective Lymphadenectomy Trial (MSLT) II trial in melanoma patients, there appeared to be a very weak trend towards improved distant disease free survival with observation compared with immediate complete LN dissection for pathologically detected metastases. These data show that removing tumor-draining LN, under certain clinical circumstances, is not beneficial. Furthermore, our data show that the targeting of the tumordraining LN with radiation may actually be deleterious for the control of distant disease. Micrometastatic disease at non-regional sites below the threshold of imaging detection or circulating tumor cells have important implications for outcomes. ${ }^{39}$ It is conceivable that tumor-draining LN irradiation in patients with previously seeded distant sites, will have reduced distant control if tumor-draining LN are included in a regimen of local T-RT. This could have a significant impact on future clinical trial design and should be a consideration going forward with active investigation of concurrent RT with or without checkpoint blockade.

Finally, data are now emerging about stem-like $\mathrm{CD} 8^{+}$ T-cells in human malignancies and human tumor-draining LN. ${ }^{40}$ Recent studies suggest a correlation between the loss of $\mathrm{CXCR}^{+} \mathrm{CD}^{+} \mathrm{T}$-cells (stem-like) and worse cancer outcomes. ${ }^{42} 43$ The impact of RT on this subset and its potential role in the abscopal effect in humans remains unknown. The results of this preclinical study yield a number of interesting hypotheses, and they will require detailed follow-up studies/clinical trials for validation and to provide a deeper mechanistic framework to fully understand these phenomena.

Correction notice This article has been corrected since it was first published. Author name has been corrected to 'Andreas Wieland' and Figure 3 has been updated to correct a duplication in Panel $\mathrm{E}$.

Twitter Zachary S Buchwald @zach_buchwald

Acknowledgements Cristian Badea: Mouse micro-CT imaging was performed at the Duke Center for In Vivo Microscopy, an NIH/NIBIB national Biomedical Technology Resource Center (P41 EB015897), and was also supported by the NIH National Cancer Institute (R01 CA196667, U24 CA220245). Eduard Schriebman, Anees Dahbaan, Jaymin Jhaveri and Nivedh Manohar for assistance with radiation dosimetry and treatment planning.

Contributors ZSB, RA, MKK, DL and WC were involved in the project conceptualization. ZSB, THN, JL, CSE and AW performed all experiments. SJI, DL, RA, MKK and ZSB were involved in data analysis. ZSB wrote the manuscript. All authors assisted with editing the manuscript. All authors read and approved the manuscript.

Funding ZSB: ASCO Young Investigator Award; RA: NIH NIAID R01; MKK: American Cancer Society- Institutional Research Grant; Seed Grant from the Melanoma Research Fund of Winship Cancer Institute.

Competing interests None declared. 
Patient consent for publication Not required.

Ethics approval IACUC approval was obtained for all animal studies.

Provenance and peer review Not commissioned; externally peer reviewed.

Data availability statement Data are available on request.

Open access This is an open access article distributed in accordance with the Creative Commons Attribution Non Commercial (CC BY-NC 4.0) license, which permits others to distribute, remix, adapt, build upon this work non-commercially, and license their derivative works on different terms, provided the original work is properly cited, appropriate credit is given, any changes made indicated, and the use is non-commercial. See http://creativecommons.org/licenses/by-nc/4.0/.

\section{ORCID iDs}

Zachary S Buchwald http://orcid.org/0000-0003-4407-7264

Andreas Wieland http://orcid.org/0000-0001-9648-7922

\section{REFERENCES}

1 Mole $\mathrm{RH}$. Whole body irradiation; radiobiology or medicine? $\mathrm{Br} J$ Radiol 1953;26:234-41.

2 Demaria S, Formenti SC. Can abscopal effects of local radiotherapy be predicted by modeling $\mathrm{T}$ cell trafficking? J Immunother Cancer 2016;4:29.

3 Formenti SC, Demaria S. Systemic effects of local radiotherapy. Lancet Oncol 2009;10:718-26.

4 Vanpouille-Box C, Formenti SC, Demaria S. Toward precision radiotherapy for use with immune checkpoint blockers. Clin Cancer Res 2018;24:259-65.

5 Reits EA, Hodge JW, Herberts CA, et al. Radiation modulates the peptide repertoire, enhances $\mathrm{MHC}$ class I expression, and induces successful antitumor immunotherapy. J Exp Med 2006;203:1259-71.

6 Dovedi SJ, Adlard AL, Lipowska-Bhalla G, et al. Acquired resistance to fractionated radiotherapy can be overcome by concurrent PD-L1 blockade. Cancer Res 2014;74:5458-68.

7 Burnette BC, Liang $\mathrm{H}$, Lee $\mathrm{Y}$, et al. The efficacy of radiotherapy relies upon induction of type I interferon-dependent innate and adaptive immunity. Cancer Res 2011;71:2488-96.

8 Vanpouille-Box C, Formenti SC, Demaria S. TREX1 dictates the immune fate of irradiated cancer cells. Oncoimmunology 2017;6:e1339857.

9 Vanpouille-Box C, Alard A, Aryankalayil MJ, et al. DNA exonuclease TREX1 regulates radiotherapy-induced tumour immunogenicity. Nat Commun 2017:8:15618.

10 Thompson ED, Enriquez HL, Fu Y-X, et al. Tumor masses support naive $T$ cell infiltration, activation, and differentiation into effectors. $J$ Exp Med 2010;207:1791-804.

11 Marzo AL, Lake RA, Lo D, et al. Tumor antigens are constitutively presented in the draining lymph nodes. J Immunol 1999:162:5838-45.

12 Roberts EW, Broz ML, Binnewies M, et al. Critical Role for CD103(+)/ CD141(+) Dendritic Cells Bearing CCR7 for Tumor Antigen Trafficking and Priming of T Cell Immunity in Melanoma. Cancer Cell 2016;30:324-36.

13 Kamphorst AO, Pillai RN, Yang S, et al. Proliferation of PD-1+ CD8 T cells in peripheral blood after PD-1-targeted therapy in lung cancer patients. Proc Natl Acad Sci U S A 2017;114:4993-8.

14 Kamphorst AO, Wieland A, Nasti T, et al. Rescue of exhausted CD8 T cells by PD-1-targeted therapies is CD28-dependent. Science 2017;355:1423-7.

15 Takeshima T, Chamoto K, Wakita D, et al. Local radiation therapy inhibits tumor growth through the generation of tumor-specific CTL: its potentiation by combination with Th1 cell therapy. Cancer Res 2010;70:2697-706.

16 Marciscano AE, Ghasemzadeh A, Nirschl TR, et al. Elective nodal irradiation attenuates the combinatorial efficacy of stereotactic radiation therapy and immunotherapy. Clin Cancer Res 2018;24:5058-5071.

17 Wherry EJ, Barber DL, Kaech SM, et al. Antigen-Independent memory CD8 T cells do not develop during chronic viral infection. Proc Natl Acad Sci U S A 2004;101:16004-9.

18 Zajac AJ, Blattman JN, Murali-Krishna K, et al. Viral immune evasion due to persistence of activated $T$ cells without effector function. $J$ Exp Med 1998;188:2205-13.

19 Gallimore A, Glithero A, Godkin A, et al. Induction and exhaustion of lymphocytic choriomeningitis virus-specific cytotoxic T lymphocytes visualized using soluble tetrameric major histocompatibility complex class I-peptide complexes. J Exp Med 1998;187:1383-93.

20 Barber DL, Wherry EJ, Masopust D, et al. Restoring function in exhausted CD8 T cells during chronic viral infection. Nature 2006;439:682-7.

21 Im SJ, Hashimoto M, Gerner MY, et al. Defining CD8+ T cells that provide the proliferative burst after PD-1 therapy. Nature 2016;537:417-21.

22 Wieland A, Kamphorst AO, Valanparambil RM, et al. Enhancing FcyRmediated antibody effector function during persistent viral infection. Sci Immunol 2018;3:eaao3125.

23 Wherry EJ, Blattman JN, Murali-Krishna K, et al. Viral persistence alters CD8 T-cell immunodominance and tissue distribution and results in distinct stages of functional impairment. $J$ Virol 2003;77:4911-27.

24 Murali-Krishna K, Altman JD, Suresh M, et al. Counting antigenspecific CD8 T cells: a reevaluation of bystander activation during viral infection. Immunity 1998;8:177-87.

25 Twyman-Saint Victor C, Rech AJ, Maity A, et al. Radiation and dual checkpoint blockade activate non-redundant immune mechanisms in cancer. Nature 2015;520:373-7.

26 Formenti SC, Rudqvist N-P, Golden E, et al. Radiotherapy induces responses of lung cancer to CTLA-4 blockade. Nat Med 2018;24:1845-51.

27 Dewan MZ, Galloway AE, Kawashima N, et al. Fractionated but not single-dose radiotherapy induces an immune-mediated abscopal effect when combined with anti-CTLA-4 antibody. Clin Cancer Res 2009;15:5379-88.

28 Deng L, Liang H, Burnette B, et al. Irradiation and anti-PD-L1 treatment synergistically promote antitumor immunity in mice. J Clin Invest 2014;124:687-95.

29 Chamoto K, Chowdhury PS, Kumar A, et al. Mitochondrial activation chemicals synergize with surface receptor PD-1 blockade for T cell-dependent antitumor activity. Proc Natl Acad Sci U S A 2017;114:E761-70

30 Fransen MF, Schoonderwoerd M, Knopf P, et al. Tumor-draining lymph nodes are pivotal in PD-1/PD-L1 checkpoint therapy. JC Insight 2018;3. doi:10.1172/jci.insight.124507

31 Luke JJ, Lemons JM, Karrison TG, et al. Safety and clinical activity of pembrolizumab and multisite stereotactic body radiotherapy in patients with advanced solid tumors. J Clin Oncol 2018;36:1611-8.

32 Eggermont AMM, Blank CU, Mandala M, et al. Adjuvant pembrolizumab versus placebo in resected stage III melanoma. $N$ Engl J Med 2018;378:1789-801.

33 Eggermont AMM, Chiarion-Sileni V, Grob J-J, et al. Prolonged survival in stage III melanoma with ipilimumab adjuvant therapy. $N$ Engl J Med 2016;375:1845-55.

34 Weber J, Mandala M, Del Vecchio M, et al. Adjuvant nivolumab versus ipilimumab in resected stage III or IV melanoma. $N$ Engl $J$ Med 2017.

35 Antonia SJ, Villegas A, Daniel D, et al. Overall survival with Durvalumab after chemoradiotherapy in stage III NSCLC. N Engl J Med 2018:379:2342-50.

36 Faries MB, Thompson JF, Cochran AJ, et al. Completion dissection or observation for sentinel-node metastasis in melanoma. $N$ Engl $J$ Med 2017;376:2211-22

37 Giuliano AE, Hunt KK, Ballman KV, et al. Axillary dissection vs no axillary dissection in women with invasive breast cancer and sentinel node metastasis: a randomized clinical trial. JAMA 2011;305:569-75.

38 Leiter U, Stadler R, Mauch C, et al. Complete lymph node dissection versus no dissection in patients with sentinel lymph node biopsy positive melanoma (DeCOG-SLT): a multicentre, randomised, phase 3 trial. Lancet Oncol 2016;17:757-67.

39 Leong SPL, Tseng WW. Micrometastatic cancer cells in lymph nodes, bone marrow, and blood: clinical significance and biologic implications. CA Cancer J Clin 2014;64:195-206.

40 Xing J, Zhang C, Yang X, et al. CXCR5 ${ }^{+} \mathrm{CD} 8^{+} \mathrm{T}$ cells infiltrate the colorectal tumors and nearby lymph nodes, and are associated with enhanced IgG response in B cells. Exp Cell Res 2017;356:57-63.

41 Zhou Y, Guo L, Sun H, et al. CXCR5 ${ }^{+}$CD8 T cells displayed higher activation potential despite high PD-1 expression, in tumor-involved lymph nodes from patients with thyroid cancer. Int Immunopharmacol 2018;62:114-9.

42 Brummelman J, Pilipow K, Lugli E. The Single-Cell Phenotypic Identity of Human CD8(+) and CD4(+) T Cells. Int Rev Cell Mol Biol 2018;341:63-124.

43 Sade-Feldman M, Yizhak K, Bjorgaard SL, et al. Defining T cell states associated with response to checkpoint immunotherapy in melanoma. Cell 2018;175:e20:998-1013. 


\section{Correction: Tumor-draining lymph node is important for a robust abscopal effect stimulated by radiotherapy}

Buchwald ZS, Nasti TH, Lee J, et al. Tumor-draining lymph node is important for a robust abscopal effect stimulated by radiotherapy. J Immunother Cancer 2020;8:e00867. doi:10.1136/jitc-2020-000867

This article has been corrected since it was first published. Author name has been corrected to 'Andreas Wieland' and Figure 3 has been updated to correct a duplication in Panel E.

Open access This is an open access article distributed in accordance with the Creative Commons Attribution Non Commercial (CC BY-NC 4.0) license, which permits others to distribute, remix, adapt, build upon this work non-commercially, and license their derivative works on different terms, provided the original work is properly cited, appropriate credit is given, any changes made indicated, and the use is non-commercial. See http://creativecommons.org/licenses/by-nc/4.0/.

(C) Author(s) (or their employer(s)) 2021. Re-use permitted under CC BY-NC. No commercial re-use. See rights and permissions. Published by BMJ.

J Immunother Cancer 2021;9:e000867corr1 . doi:10.1136/jitc-2020-000867corr1

(A) Check for updates 